\title{
Effect of Seedborne Potato virus $Y$ on Performance of Russet Burbank, Russet Norkotah, and Shepody Potato
}

Phillip Nolte, University of Idaho, Idaho Falls 83402; Jonathan L. Whitworth, United States Department of Agriculture-Agricultural Research Service, Aberdeen, ID 83210; Michael K. Thornton, University of Idaho, Parma 83660; and Christopher S. McIntosh, University of Idaho, Idaho Falls

\begin{abstract}
Nolte, P., Whitworth, J. L., Thornton, M. K., and McIntosh, C. S. 2004. Effect of seedborne Potato virus $Y$ on performance of Russet Burbank, Russet Norkotah, and Shepody potato. Plant Dis. 88:248-252.

Potato virus $Y(\mathrm{PVY})$ is one of the most important of the potato viruses, but little is known about the impact on yield of seedborne infection levels below 100\%. Blending infected and healthy seed from different seed lots introduces the variable of performance differences between the seed lots, which may obscure the effect of virus alone. Seed lots containing various levels of seedborne PVY $(0,2,10,20$, and $50 \%$ incidence of infected tubers) were created by combining in different proportions seed pieces from healthy and infected tubers from the same seed source. These seed lots were planted in replicated field plots at the University of Idaho Parma R \& E Center in Parma, ID from 1995 to 1997. Regression analyses on data from the three consecutive seasons indicate that seedborne PVY has virtually the same negative impact on yield for all three cultivars.
\end{abstract}

Additional keywords: seedborne virus

Potato virus $Y$ (PVY) is one of the most important virus diseases of potato and can be responsible for yield losses of 10 to $80 \%$, depending on the cultivar (2). Significant time and effort is expended worldwide to produce seed potato crops containing very low or undetectable levels of this virus. Unfortunately, PVY infection in some of the newer North American cultivars, such as Shepody and Russet Norkotah, frequently results in mild or even latent symptoms as opposed to the typical foliar mosaic symptoms that are readily observed in more traditional cultivars like Russet Burbank (6). The lack of clear, identifiable symptoms means that producing certified seed of Russet Norkotah and Shepody can be difficult, because production methods for certified seed potato in the United States still rely heavily on visual inspection procedures for detection and removal of PVY-infected plants (1). The mild symptom expression in these cultivars has led both seed and commercial potato producers to conclude that Shepody and Russet Norkotah are more "tolerant" of

Corresponding author: P. Nolte

E-mail: pnolte@uidaho.edu

This research project was performed, in part, with the support of a grant from the Idaho Potato Commission.

Accepted for publication 3 October 2003.

Publication no. D-2003-1216-03R

(C) 2004 The American Phytopathological Society
PVY and, thus, would suffer less yield loss than Russet Burbank for a given percentage of seedborne virus (6).

Although PVY has been reported to be a yield-limiting factor in potato production, the range in degree of symptom expression among cultivars is not considered to be a reliable indicator of the yield reduction that occurs in PVY-infected plants $(6,10)$. PVY, in combination with potato early dying, decreased yield by $70 \%$ in Russet Norkotah (8). A commercial planting of cv. Morene was reported to have suffered a yield loss of 5 to $7 \%$ because of $18 \%$ seedborne PVY (5). Yield reductions of 29 to $59 \%$ due to seedborne PVY infection were reported in cvs. Bintje, Record, Sabina, and Matilda (7).

The objective of this study was to compare the effect of various levels of seedborne PVY infection on yield of Russet Burbank, a cultivar that displays typical mosaic foliar symptoms, with Russet Norkotah and Shepody, cultivars that show very mild symptoms as a result of PVY infection.

\section{MATERIALS AND METHODS}

Potato seed performance can be quite variable among seed lots. To obtain seed for studying the effect of various infection levels of PVY on yield, it was desirable to have quantities of seed tubers with known percentages of the tubers infected with PVY. Ideally, both healthy and infected tubers should be from the same seed lot to eliminate lot-to-lot variability in seed performance. For this study, seed lots with various target levels of PVY were created by growing inoculated and noninoculated portions of the same seed lot in very close proximity in a small field plot, harvesting tubers from the inoculated and noninoculated plants at the same time, and storing them in the same facility under the same conditions. In the spring, tubers from healthy plants and from PVY-infected plants were cut into seed pieces, which then were combined in different ratios of healthy to PVY-infected seed pieces to produce seed lots with the desired percentages of PVY infection. This procedure was carried out in an attempt to eliminate variability in performance among seed lots.

Seed production. Seed production for all 3 years of the study was performed at the Colorado State University facility in Center, CO. Seed tubers from certified seed lots (field generation 2) of Russet Burbank, Russet Norkotah, and Shepody that had tested free of Potato leaf roll virus (PLRV) and PVY in both the summer and winter inspections were used to produce seed for the study. Seed tubers were planted in four $30-\mathrm{m}$ rows spaced $0.9 \mathrm{~m}$ apart, with hills spaced $30 \mathrm{~cm}$ apart within the row on 5 May 1994, 16 May 1995, and 15 May 1996. An additional two rows, which remained noninoculated and served as the source of noninfected seed tubers, was planted at least $4 \mathrm{~m}$ away from inoculated rows each year. The set of four rows per cultivar was inoculated mechanically with PVY on 13 June 1994, 16 June 1995 , and 20 June 1996, according to the protocol described below. A second inoculation was made 1 to 3 weeks later on plants that had not emerged at the time of the first inoculation. The same plot plan was utilized in all three years of the study.

Inoculum source and maintenance. The PVY strain used for the duration of the experiment was determined to be a form of strain group 01 by Peter Ellis of Phyto Diagnostics (Sydney, BC, Canada) using a monoclonal antibody technique (3). Tubers were harvested from two plants of cv. Crestone Russet in a seed producer's field near Center, $\mathrm{CO}$ that were infected naturally with PVY and also had tested negative for PLRV, Potato virus X (PVX), and Potato virus $S$ (PVS). Six tubers from each plant were planted into $30-\mathrm{cm}$ diameter black plastic pots containing an artificial soil mix (Sunshine \#1; Sun Gro Horticulture, Inc., Bellevue, WA) and 
maintained in a glasshouse. These plants also were tested for PVY, PLRV, PVX, and PVS using the direct tissue-blotting assay (DTBA), a serological technique which is similar in principle and accuracy to enzyme-linked immunosorbent assay (11). Of these 12 plants, 2 plants, both of which had tested positive for PVY and negative for all of the other viruses, were selected to provide infected foliar tissue for preparation of PVY inoculum for the field inoculations, and to provide infected tubers for replanting in the glasshouse to maintain an available source of virus. Diseased plants were maintained in the glasshouse until the foliage began to decline (approximately 4 months), at which time the tubers were harvested and held at $20^{\circ} \mathrm{C}$ until they began to break dormancy. These tubers then were planted in the glasshouse in the same manner as the original tubers. This "serial planting" technique of harvesting and planting tubers from source plants was repeated continuously over the course of the experiment. Glasshouse-harvested tubers produced plants that emerged and developed at different rates, meaning that PVY-infected source plants at several stages of maturity were growing concurrently. These methods were employed to ensure that sufficient quantities of infected foliar tissue at the proper stage of maturity were available when needed for preparation of inoculum for the field inoculations. Plants selected for use as inoculum sources for the inoculation of the field-grown seed were approximately 10 weeks old. Each year, the source plants in the glasshouse were tested for PVY, PVX, and PVS using the DTBA before inoculations were attempted. SCIL Diagnostics (Martinsread, Germany) was the source of antiserum for the DTBA testing.

Field inoculations were performed when plants were $10 \mathrm{~cm}$ tall, using a procedure developed by E. Bantari (personal communication). Infected leaf tissue from the Crestone source plants was macerated in a chilled blender with a potassium phosphate buffer at a ratio of $150 \mathrm{~g}$ of leaf tissue per $500 \mathrm{ml}$ of buffer. The inoculation buffer was prepared using a 1:10 dilution (wt/vol) of a stock solution $\left(0.5 \mathrm{M} \mathrm{K}_{2} \mathrm{HPO}_{4}, 0.5 \mathrm{M}\right.$ $\mathrm{KH}_{2} \mathrm{PO}_{4}$, and $\left.0.2 \% \quad \mathrm{NaSO}_{3}, \mathrm{pH} 7.5\right)$ to which $5 \mathrm{~cm}^{3}$ of carborundum (500 mesh, Fisher Chemical, Pittsburgh, PA) per liter was added. The solution then was filtered through cheesecloth into the chilled stainless steel reservoir container of an automotive-type paint sprayer (Devilbiss, Maumee, $\mathrm{OH}$ ). The sprayer was adjusted to apply the solution at $7.0323 \mathrm{~kg} / \mathrm{cm}(6.89$ bar). The nozzle of the spray gun was held approximately $15 \mathrm{~cm}$ from the target plant and each plant received a blast of the inoculum solution until all of the leaves were wet (approximately $3 \mathrm{~s}$ ).

All plants in the field plots were tested for PVY, PVX, PVS, and PLRV on 17 August 1994, 14 August 1995, and 26
August 1996 using the DTBA. PVX was not detected, but PVS was found in all plants assayed. Vines were killed by application of diquat dibromide (Reglone; Syngenta, Greensboro, NC) at the rate of 1.15 liters/ha in 280 liters of water. Plants that tested positive for PVY were flagged and the tubers harvested by hand when the vines were completely dead, 3 weeks after vine kill. Healthy plants also were flagged and harvested. For this study, healthy plants are defined as testing negative for PLRV, PVX, and PVY and testing positive for PVS . Infected plants were defined as testing positive for PLRV and PVX and testing positive for PVY and PVS. Seed tubers from both healthy and infected plants then were stored in a walk-in cooler maintained at $3.3^{\circ} \mathrm{C}$ and $80 \%$ relative humidity until used the following spring.

Percent seedborne PVY versus yield. The field experiments were performed at the University of Idaho Parma Research and Extension Center in Parma, ID in a randomized complete block design that incorporated four replications. Seed pieces were planted in paired rows of 25 seed pieces each, and each plot also included a one-row border on either side of the paired rows. To reduce current-season spread of PVY by noncolonizing aphids, a 2-m buffer zone of Sudan grass, (24 rows of cv. Trudan 8), was planted around the edge of the whole experiment. Seed tubers from

Table 1. Seedborne Potato virus $Y$ (PVY): target versus actual detected incidence (\%) of plants (tubers) infected in 1995 to 1997 (mean of four replications per year) ${ }^{\mathrm{a}}$

\begin{tabular}{lccc}
\hline & \multicolumn{3}{c}{ Incidence (\%) detected $^{\mathbf{b}}$} \\
\cline { 2 - 4 } Cultivar, target PVY (\%) & $\mathbf{1 9 9 5}$ & $\mathbf{1 9 9 6}$ & $\mathbf{1 9 9 7}$ \\
\hline Russet Burbank & & & \\
0 & 2.8 & 0.0 & 2.9 \\
2 & 6.6 & 1.0 & 4.3 \\
10 & 1.0 & 8.9 & 8.3 \\
20 & 10.0 & 17.4 & 17.0 \\
50 & 17.1 & 51.4 & 14.0 \\
80 & $\ldots$ & 78.4 & $\ldots$ \\
100 & $\ldots$ & 89.3 & $\ldots$ \\
Russet Norkotah & & & 11.6 \\
0 & 1.8 & 11.4 & 13.4 \\
2 & 9.8 & 6.1 & 18.6 \\
10 & 10.5 & 12.4 & 25.8 \\
20 & 9.1 & 22.6 & 48.9 \\
50 & 16.2 & 43.1 & $\ldots$ \\
80 & $\ldots$ & 80.8 & $\ldots$ \\
100 & $\ldots$ & 98.5 & 23.4 \\
Shepody & & & 14.8 \\
0 & 4.0 & 12.3 & 28.5 \\
2 & 6.8 & 8.0 & 44.4 \\
10 & 5.9 & 16.1 & 57.3 \\
20 & 16.6 & 35.6 & $\ldots$ \\
50 & 24.50 & 58.0 & $\ldots$ \\
80 & $\ldots$ & 66.1 & \\
100 & $\ldots$ & 88.7 & \\
\hline
\end{tabular}

${ }^{a}$ Plots were established at the University of Idaho, Parma Research and Extension Center, Parma, ID.

${ }^{\mathrm{b}}$ PVY incidences were determined by enzyme-linked immunosorbent assay testing of single leaves from 50 individual plants per plot.

${ }^{c}$ Target incidence. The attempt to establish plots with selected target incidences of PVY was accomplished by combining seed pieces produced by cutting tubers harvested from plants that had tested positive for PVY in the Colorado seed-production plots during the previous year with the appropriate number of seed pieces cut form tubers harvested from plants that had tested negative for PVY in the Colorado seed-production plots in the previous year. the healthy and PVY-infected portions of hand cut into 50- to 70-g seed pieces. Healthy and infected seed pieces, mixed in domly into paper bags ( 25 seed pieces per bag for a total of 50 seed pieces per plot) seed pieces within each respective plot. eed was cut, combined into the desired seed pieces, and planted on 18 April 1995. The amount of infected seed produced for the 1995 plots allowed for target levels of $0,2,10,20$, and 50\% seedborne PVY levels selected represented several percentages of seedborne virus that are significant Noninfected seed $(0 \%)$ was included as the control. The $2 \%$ level represents the maxiseed stocks intended for recertification (seed that can be replanted in the seed program to be increased at least one more season before being sold for commercial the maximum incidence of PVY infection allowed, at the time these experiments for commercial planting in Idaho (1). The $\%$ and higher levels were included to investigate the effects on yield of moderate to very high levels of seedborne PVY. 
Seed was cut and blended on 16 April and planted on 17 April 1996. The amount of infected seed produced for the 1996 plots was sufficient for the addition of 80 and $100 \%$ PVY treatments for all three cultivars. Seed was cut, blended and planted on 3 April 1997. The amount of infected seed produced for the 1997 plots allowed for levels of 0, 2, 10, 20, and 50\% seedborne PVY treatments for all three cultivars. A single leaflet from each emerged plant in each plot was removed for PVY testing on 4 June and again on 26 July 1995. The same procedure was utilized in the following 2 years of the study, with leaflets removed for PVY testing on
10 June and 22 July 1996 and 1997. Actual percentages of plants infected with PVY were recorded for each plot for use in the statistical analyses. Vines were killed using a two-row flail-type mower, approximately 3 weeks before harvest. Plots were harvested with a two-row potato lifter on 5 September 1995, 19 September 1996, and 9 September 1997. Tubers left on the soil surface by the lifter were harvested by hand into 50-kg burlap bags and weighed to determine yield.

Statistical analysis. The detected incidences of PVY recorded for the plots varied, in some cases considerably, from the target levels; therefore, regression analysis

Table 2. Means, standard deviations, and coefficients of variation for total yield in tonnes/hectare (t/ha) of Russet Burbank, Russet Norkotah, and Shepody in 1995, 1996, and 1997

\begin{tabular}{lccc}
\hline Data & Russet Burbank & Russet Norkotah & Shepody \\
\hline Year 1 & & & \\
Mean (t/ha) & 40.40 & 49.90 & 48.22 \\
Standard deviation & 5.85 & 4.86 & 5.09 \\
Coefficient of variation & 0.14 & 0.10 & 0.11 \\
Year 2 & & & \\
Mean (t/ha) & 30.89 & 35.50 & 39.75 \\
Standard deviation & 9.22 & 10.23 & 6.51 \\
Coefficient of variation & 0.30 & 0.29 & 0.16 \\
Year 3 & & & \\
Mean (t/ha) & 52.74 & 54.09 & 58.44 \\
Standard deviation & 5.63 & 7.01 & 8.89 \\
Coefficient of variation & 0.11 & 0.13 & 0.15 \\
\hline
\end{tabular}

${ }^{a}$ Plots were established at the University of Idaho Parma Research and Extension Center in Parma, ID. Experimental units (plots) were arranged in a randomized complete block design and consisted of four replications of paired rows containing 25 plants per row with $30-\mathrm{cm}$ spacing between plants and $900-\mathrm{cm}$ spacing between rows. Total yield ( $\mathrm{t} / \mathrm{ha}$ ) was calculated on the combined yield of all 50 plants in each plot. was used to measure the negative impacts of different levels of seedborne PVY on yield and the statistical significance of this yield loss. The yield data was analyzed using ordinary least squares regression analysis (9). A regression analysis of data for the 3 years was performed for each cultivar. The following model was estimated: Yield $=b_{\mathrm{o}}+b_{1} \mathrm{PVY}+b_{2} \mathrm{Y} 2 \mathrm{D}+b_{1}$ $\mathrm{Y} 3 \mathrm{D}+\varepsilon$, where yield is the total yield in metric tons (t)/ha, PVY is the actual incidence $(\%)$ of plants infected with PVY, $\mathrm{Y} 2 \mathrm{D}=1$ for year 2 and 0 otherwise, $\mathrm{Y} 3 \mathrm{D}$ $=1$ for year 3 and 0 otherwise, the $b_{\mathrm{i}}$ are the parameters estimated by the regression, and $\varepsilon$ is an error term assumed to have the desirable statistical properties. The effect of Y2D and Y3D in the model is to allow the intercept of the yield reduction curve to change from year to year. A model allowing for different slopes $\left(b_{\mathrm{i}}\right)$ of the yield reduction curve in each year was tested for each cultivar. For all three cultivars, the models failed to reject the null hypothesis that the slopes in each year were identical. Thus, the model indicated above was deemed appropriate. A model with separate slopes for each year would indicate that the impact of the virus varied depending on growing conditions. Using a single common slope among years indicated that the virus had the same impact on yield each year.

\section{RESULTS AND DISCUSSION}

The incidence $(\%)$ of plants that tested positive for PVY varied from the target

Table 3. Ordinary least squares regression results and summary statistics on total yield of Russet Burbank, Russet Norkotah, and Shepody in 1995, 1996, and 1997

\begin{tabular}{|c|c|c|c|c|c|}
\hline Variable $^{a}$ & Coefficient $^{\mathbf{b}}$ & Standard error $^{\mathrm{c}}$ & $t$ Statistic $^{\mathrm{d}}$ & Prob. $>|t|^{\mathrm{e}}$ & Summary statistics \\
\hline \multicolumn{6}{|l|}{ Russet Burbank } \\
\hline Intercept & 41.313 & 1.308 & 31.570 & $9.76 \mathrm{E}-41$ & $\ldots$ \\
\hline PVY percentage & -0.196 & 0.031 & -6.392 & $2.14 \mathrm{E}-08$ & $\ldots$ \\
\hline Year 2 intercept shift & -3.506 & 1.945 & -1.802 & 0.076 & $\ldots$ \\
\hline Year 3 intercept shift & 13.157 & 1.844 & 7.134 & $1.08 \mathrm{E}-09$ & \\
\hline$R^{2}$ & $\ldots$ & $\ldots$ & $\ldots$ & $\ldots$ & 0.762 \\
\hline Adjusted $R^{2}$ & $\ldots$ & $\ldots$ & $\ldots$ & $\ldots$ & 0.751 \\
\hline \multicolumn{6}{|l|}{ Russet Norkotah } \\
\hline Intercept & 52.075 & 1.620 & 32.146 & $3.28 \mathrm{E}-41$ & $\ldots$ \\
\hline PVY percentage & -0.167 & 0.035 & -4.795 & $1.01 \mathrm{E}-05$ & $\ldots$ \\
\hline Year 2 intercept shift & -10.009 & 2.233 & -4.482 & $3.13 \mathrm{E}-05$ & $\ldots$ \\
\hline Year 3 intercept shift & 7.664 & 2.316 & 3.309 & 0.001 & $\ldots$ \\
\hline$R^{2}$ & $\ldots$ & $\ldots$ & $\ldots$ & $\ldots$ & 0.651 \\
\hline Adjusted $R^{2}$ & $\ldots$ & $\ldots$ & $\ldots$ & $\ldots$ & 0.634 \\
\hline \multicolumn{6}{|l|}{ Shepody } \\
\hline Intercept & 49.968 & 1.406 & 35.537 & $7.49 \mathrm{E}-44$ & $\ldots$ \\
\hline PVY percentage & -0.160 & 0.034 & -4.643 & $1.76 \mathrm{E}-05$ & $\ldots$ \\
\hline Year 2 intercept shift & -3.696 & 2.050 & -1.803 & 0.076 & $\ldots$ \\
\hline Year 3 intercept shift & 12.251 & 1.965 & 6.234 & 4.01 E-08 & \\
\hline$R^{2}$ & $\ldots$ & $\ldots$ & $\ldots$ & $\ldots$ & 0.821 \\
\hline Adjusted $R^{2}$ & $\ldots$ & $\ldots$ & $\ldots$ & $\ldots$ & 0.659 \\
\hline
\end{tabular}

${ }^{\text {a }} \mathrm{PVY}=$ Potato virus $Y . R^{2}$ is the coefficient of multiple determination and provides a percentage measure of the amount of variation in the dependent variable (market yield) that is explained by the independent variables. For Russet Burbank, the independent variables explain $76.2 \%$ of the variation in market yield. Adjusted $R^{2}$ adjusts the value of $R^{2}$ for the number of explanatory variables in the model. It is a better basis for comparison of regression models than is $R^{2}$.

${ }^{\mathrm{b}}$ Estimates for the coefficients corresponding to each variable obtained from the ordinary least squares regression.

${ }^{\mathrm{c}}$ Standard errors of the estimated coefficients obtained from the ordinary least squares regression.

${ }^{\mathrm{d}}$ For the null hypothesis Ho: the coefficient $=0$.

${ }^{e}$ Prob. $>|t|$ gives the lowest level of precision at which you would fail to reject the null hypothesis. For example, a Prob. $>|t|$ equal to 0.076 would indicate that the null hypothesis would be rejected at the $10 \%$ level, but you would fail to reject it at the $5 \%$ level of significance. 
levels in 1995 for all three cultivars, with the incidences generally lower than the target levels, especially when higher incidences were desired. Virus incidences were much closer to the PVY target levels in 1996 and 1997 for most plots of Russet Burbank, whereas the desired virus levels were higher than the target amounts in the two lowest percentage plots of Shepody and Norkotah in 1996 and 1997 (Table 1). There are several possible reasons for these discrepancies in target versus observed incidences of plants infected with PVY. Even though the vines were killed before aphids were detected in traps adjacent to the Colorado seed plots, there could have been some late-season virus spread due to aphid activity. Serological tests performed to detect late-season virus spread in the field may not detect all infected plants. Late-season virus spread may explain why the plots with targeted incidences of $0 \%$ PVY, grown from putatively healthy tubers, had as high as $15 \%$ incidence of PVY. The lower detected incidence of PVY than that targeted in 1995 and 1997 probably was due to the fact that tubers harvested from plants that tested positive for PVY were assumed to be infected, but the tubers were not tested directly. PVY is not necessarily distributed uniformly in an infected plant, and some of the lateral buds on the progeny tubers may not have been infected (4). This may explain why plots with 20 and $50 \%$ targeted levels of PVY infection had incidences of PVY lower than the target percentages in 1995 and again in 1997.

Mean yield data is presented for all three cultivars in each year in Table 2. Seasonal differences were readily apparent, with 1997 having the highest yields and 1996 having the lowest. This result was consistent for all three cultivars. The regression analysis for yield of Russet Burbank demonstrated a correlation coefficient $\left(R^{2}\right)$ of 0.8259 (Table 3$)$. This meant that $82 \%$ of the variation in yield was explained by the regression model. The table contains the parameter estimates for the $b_{\mathrm{i}}$ along with their standard errors, $t$ statistics, and $P$ values. The $t$ statistics are for the hypothesis test Ho: $b_{\mathrm{i}}=0$. For all $b_{\mathrm{i}}$, this hypothesis is rejected at any reasonable level of significance and we conclude that the parameter estimates are, indeed, significantly different from zero.

The impact of including intercept shifters by showing a separate trend line for each year is illustrated in Figure 1. The results indicate that, although allowances must be made for differences in growing conditions from one year to the next, the impact of PVY on yield is the same within each year.

Yield was found to be reduced by $0.1805 \mathrm{t} / \mathrm{ha}$ for each $1 \%$ increase in PVY. To put this in terms of lost income, assuming that potato tubers are, on average, worth $\$ 99.2 / t$, this would represent a de- crease in gross revenue of $\$ 17.91 /$ ha. This dollar amount is applicable in each year of the study.

Yield analysis for cv. Russet Norkotah is shown in Table 3 and Figure 2. The $R^{2}$ of 0.6751 indicated that $67 \%$ of the variation in yield was explained by the three variables in the model. The $t$ statistics indicate that Ho: $b_{\mathrm{i}}=0$ would be rejected for all $b_{\mathrm{i}}$ at the 0.05 level of significance. A $b_{1}$ of -1.6080 indicates that, for each percentage of increase in PVY, yield declines by $0.1802 \mathrm{t} / \mathrm{ha}$. Again, assuming that potato tubers are worth, on average, $\$ 99.2 / \mathrm{t}$, this would represent a decrease in gross revenue of $\$ 17.88 / \mathrm{ha}$. This dollar amount is

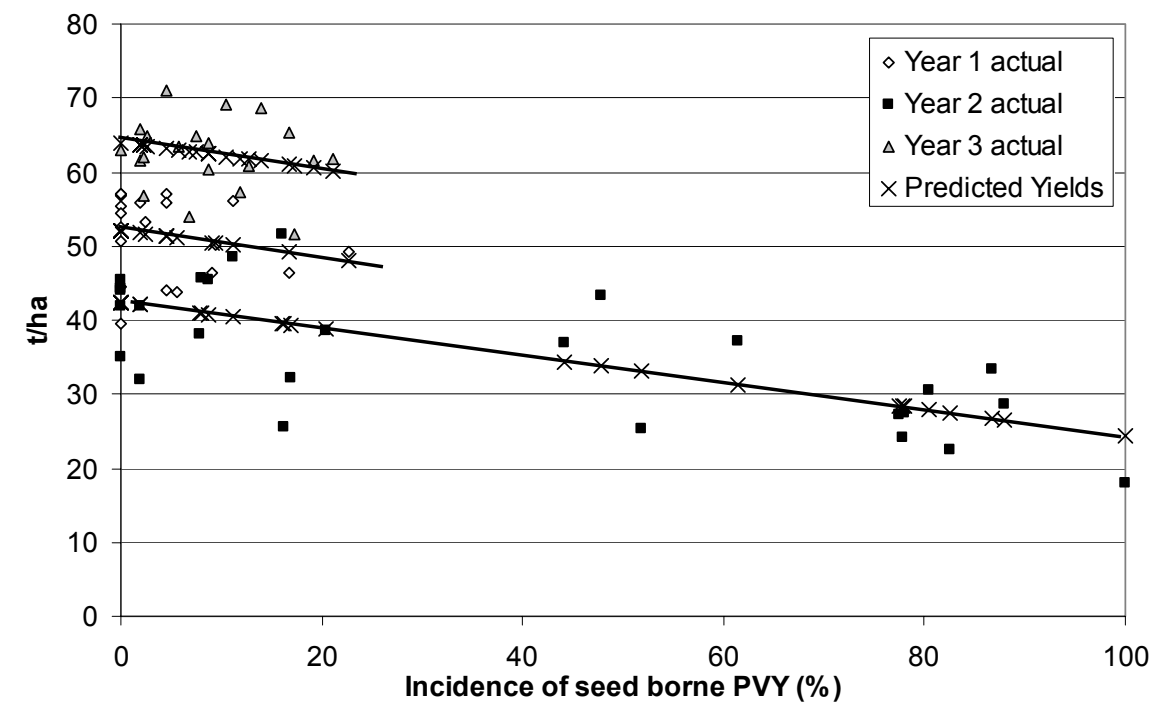

Fig. 1. Ordinary least squares regression of percent seedborne Potato virus $Y$ (PVY) versus yield in tonnes/hectare (t/ha) for 3 years of replicated field trials in Russet Burbank potato. Predicted values were calculated using the regression results. Actual values were observed in the trials. Plots were established at the University of Idaho Parma Research and Extension Center in Parma, ID. Experimental units (plots) were arranged in a randomized complete block design and consisted of four replications of paired rows containing 25 plants per row with $30-\mathrm{cm}$ spacing between plants and $900-\mathrm{cm}$ spacing between rows. Each data point represents the total yield of a single plot and was calculated on the combined yield of all 50 plants in each plot.

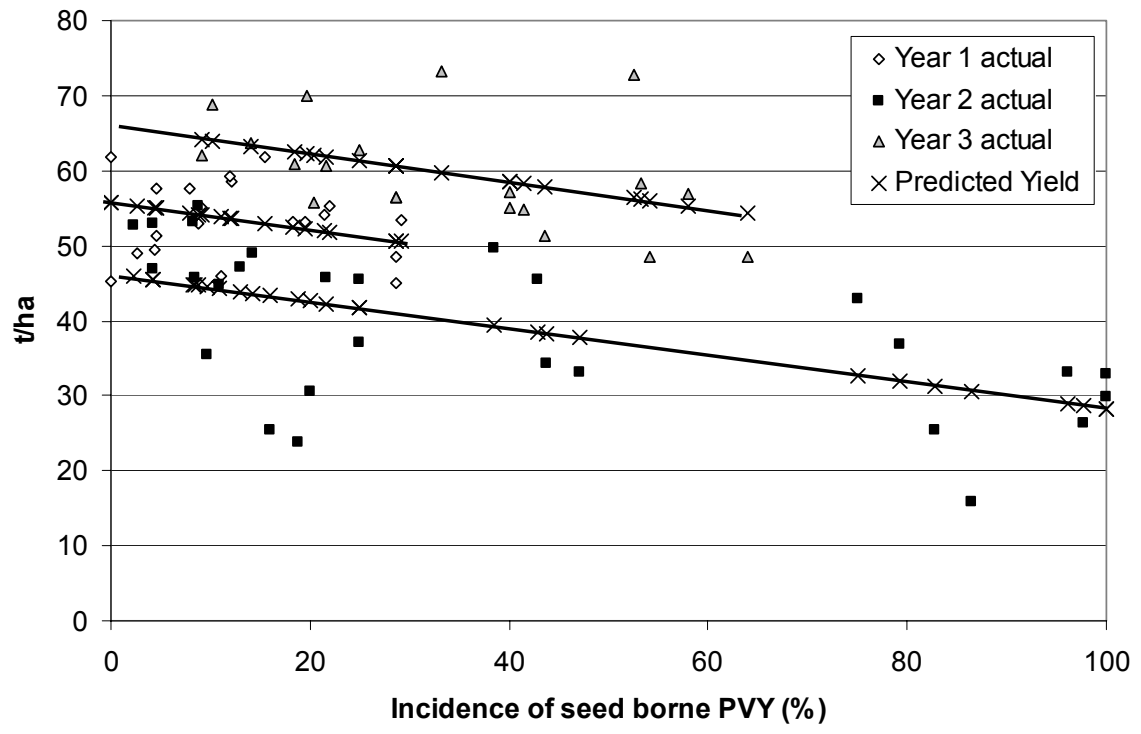

Fig. 2. Ordinary least squares regression of percent seedborne Potato virus $Y$ (PVY) versus yield in tonnes/hectare ( $\mathrm{t} / \mathrm{ha}$ ) for 3 years of replicated field trials in Russet Norkotah potato. Predicted values were calculated using the regression results. Actual values were observed in the trials. Plots were established at the University of Idaho Parma Research and Extension Center in Parma, ID. Experimental units (plots) were arranged in a randomized complete block design and consisted of four replications of paired rows containing 25 plants per row with 30-cm spacing between plants and $900-\mathrm{cm}$ spacing between rows. Each data point represents the total yield of a single plot and was calculated on the combined yield of all 50 plants in each plot. 


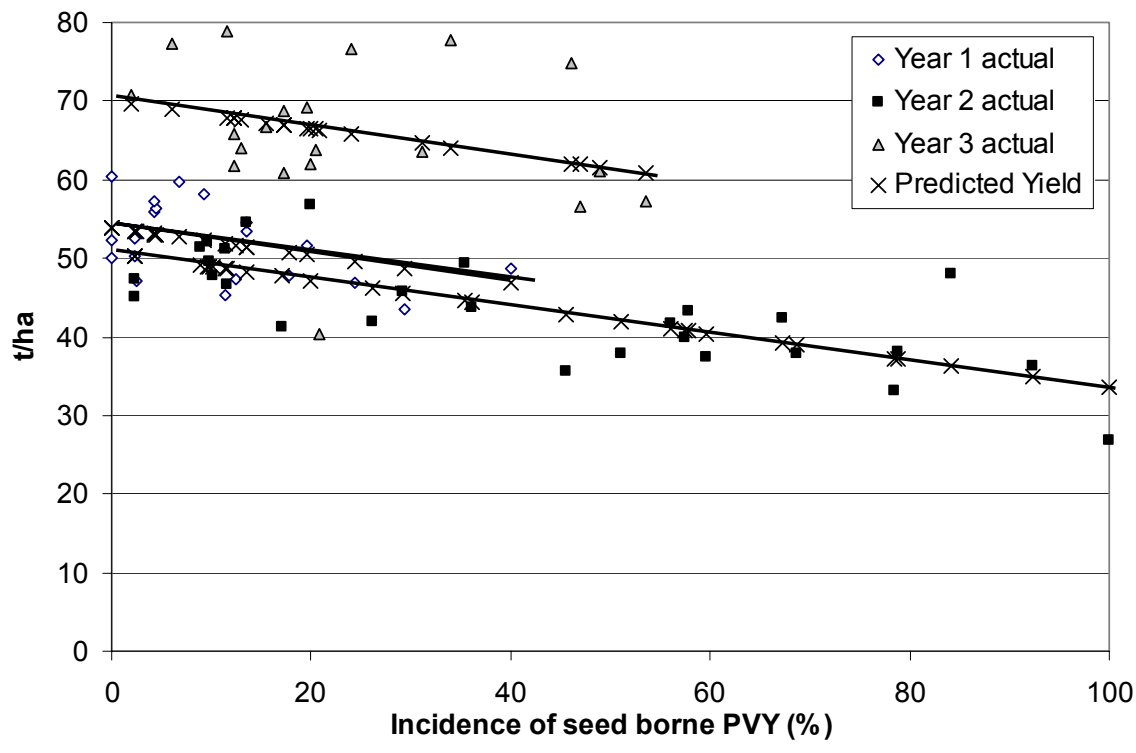

Fig. 3. Ordinary least squares regression of percent seed borne Potato virus $Y$ (PVY) versus yield in tonnes/hectare $(\mathrm{t} / \mathrm{ha})$ for 3 years of replicated field trials in Shepody potato. Predicted values were calculated using the regression results. Actual values were observed in the trials. Plots were established at the University of Idaho Parma Research and Extension Center in Parma, ID. Experimental units (plots) were arranged in a randomized complete block design and consisted of four replications of paired rows containing 25 plants per row with $30-\mathrm{cm}$ spacing between plants and $900-\mathrm{cm}$ spacing between rows. Each data point represents the total yield of a single plot and was calculated on the combined yield of all 50 plants in each plot.

applicable in each year of the study. The three separate trend lines estimated from the regression are shown in Figure 2. The significance of the $b_{2}$ and $b_{3}$ variables indicates that separate year trend lines are appropriate.

Yield results for cv. Shepody are shown in Table 3 and Figure 3. The $R^{2}$ of 0.7316 indicated that $73 \%$ of the variation in yield was explained by the three variables in the model. The $t$ statistics indicate that Ho: $b_{\mathrm{i}}$ $=0$ would be rejected for all $b_{\mathrm{i}}$ except $b_{2}$ at the 0.05 level of significance. The parameter estimate for $b_{2}$ is not significantly different from zero at the 0.05 level, but is significantly different from zero at the 0.14 level. We include $b_{2}$ in the model even though it can be deemed insignificant by stricter standards. If we were to eliminate this variable from the model, the trend line for years 1 and 2 would be coincidental. A $b_{1}$ of -1.5225 indicates that, for each percentage of increase in PVY, yield declines by $0.1709 \mathrm{t} / \mathrm{ha}$. Again, assuming that potato tubers are worth, on average, $\$ 99.2 / \mathrm{t}$, this would represent a decrease in gross crease of seedborne PVY results in a definable yield loss at harvest. With this knowledge, the commercial grower can make educated decisions about what level of PVY mosaic virus constitutes an acceptable risk in the seed purchased for planting.

The results of this experiment demonstrated that the greater the incidence of PVY in a seed lot, the more total yield is reduced for the cultivars evaluated. Surprisingly, the amount of yield loss for each $1 \%$ increase in seedborne PVY remained the same for all of the cultivars among years, even though total yields varied considerably among years. For Shepody and Norkotah, despite a tendency for less severe symptoms of PVY infection, the virus was responsible for yield reductions very similar to those observed in Russet Burbank, for all 3 years of this study.

\section{LITERATURE CITED}

1. Anonymous. 2003. Idaho Rules of Certification. Idaho Crop Improvement Association, Meridian, ID.

2. de Bokx, J. A., and Huttinga, H. 1981. Potato Virus Y. Descriptions of Plant Viruses, No. 242. Commonwealth Mycological Institute and Association of Applied Biologists, Kew, England.

3. Ellis, P., Stace-Smith, R., and de Villiers, G. 1997. Identification and geographic distribution of serotypes of potato virus Y. Plant Dis. 81:481-484.

4. Gibbs, A., and Harrison, B. 1976. Plant Virology: The Principles. John Wiley and Sons, Inc., New York.

5. Gladders, P., and Campbell-Hill, C. E. 1988 Effect of potato virus $\mathrm{Y}$ on the yield of potato cultivar Morene. Tests of Agrochemicals and Cultivars 9. Ann. Appl. Biol. (Suppl.) 112:90 91.

6. Hane, D. C., and Hamm, P. B. 1999. Effects of seed borne potato virus $\mathrm{Y}$ infection in two potato cultivars expressing mild disease symptoms. Plant Dis. 83:43-45.

7. Kurppa, A., and Hassi A. 1989. Reaction of four table potato cultivars to primary and secondary infection by potato viruses Yo and Yn. Ann. Agric. Fenn. 28:297-307.

8. Mondjana, A.M., Rouse, D. I., and German, T. L. 1993. The impact of PVY on potato yield and severity of early dying. (Abstr.) Am. Potato J. 70:829.

9. Neter, J., Wasserman, W., and Kutner, M. H 1989. Applied Linear Regression Models. Irwin, Boston.

10. Rykbost, K. A., Hane, D. C., Hamm, P. B., Voss, R., and Kirby, D. 1999. Effects of seedborne potato virus Y on Russet Norkotah performance. Am. J. Potato Res. 76:91-96.

11. Sampson, R. G., Allen, T. C., and Whitworth, J. L. 1993. Evaluation of direct tissue blotting to detect potato viruses. Am. Potato J. 70:257-265. 